\title{
Aquinas's Impediment Argument for the Spirituality of the Human Intellect
}

\section{DAVID P. LANG}

Wentworth Institute of Technology, Boston

In several texts, Thomas Aquinas employs a controversial demonstration for the spirituality (that is, intrinsic independence from matter) of the human potential intellect - an argument deriving from a famous, though somewhat abstruse, passage in Book III of Aristotle's De Anima ${ }^{1}$. Because Aquinas's development of this intriguing proof can itself be accused of insufficient rigor, rendering it susceptible to objections, it behooves us to explore this problem from the beginning. Hence, at the very outset, I reproduce two standard translations of the controverted passage from Aristotle's treatise on psychology:

Therefore, since everything is a possible object of thought, mind, in order, as Anaxagoras says, to dominate, that is, to know, must be pure from all admixture; for the co-presence of what is alien to its nature is a hindrance and a block: it follows that it too, like the sensitive part, can have no nature of its own, other than that of having a certain capacity. Thus that in the soul which is called mind (by mind I mean that whereby the soul thinks and judges) is, before it thinks, not actually any real thing. For this reason it cannot reasonably be regarded as blended with the body: if so, it would acquire some quality, e.g. warmth or cold, or even have an organ like the sensitive faculty: as it is, it has none. It was a good idea to call the soul "the place of forms," though (1) this description holds only of the intellective soul, and (2) even this is the forms only potentially, not actually. ${ }^{2}$

And, since the intellect [can] think every [object of thought], it must exist without being blended [with something else] in order that, as Anaxagoras says, "it may rule," that is, in order that it may know. For, if it appears along [with some other thing], the [latter will] prevent or obstruct [the knowledge of] another kind [of thing]; hence it is necessary for [the intellect] to be of no nature other than that of [mere] potentiality. So the part of the soul which is called "intellect" (by

1. Summa Theologiae I, q. 75, a. 2; Quaestiones De Anima, qq. 2, 14; In III De Anima, lect. 7, n. 680 .

2. De Anima III, 4: 429a19-29, trans. J. A. Smith, in The Basic Works of Aristotle, ed. Richard McKeon (New York: Random House, 1941), pp. 589-90. 
"intellect" I mean that [part] by which the soul [can] think and believe) is actually none of the things prior to thinking. In view of this, it is not even reasonable that it should be blended with the body, for it might then acquire some quality, e.g., coldness or heat, or there might be even an organ [for it], as there is for the sentient power; but, as it is, there is no [such organ]. So those who say that the soul is a place of forms speak well, except that it is not the whole soul but only the thinking part of it, and that [that part] is not actually but potentially the forms [of things]. ${ }^{3}$

Here, both translations concur, Aristotle explicitly attributes a fundamental insight about immateriality to Anaxagoras, who held that a ruling Mind exercises ultimate control in cosmic governance. ${ }^{4}$ According to this pre-Socratic philosopher, this Mind's pervasive or all-encompassing superiority over the material universe demands that it itself be devoid of any contaminating interference by matter. He might have reasoned, we speculate, that, if it did enter into any composition with matter, it would perforce be responsible for arranging the structure of its very own being-a sort of self-referential inconsistency (more precisely, a contradiction committed by violating the maxim that something cannot give itself what it does not have).

Aristotle, however, appropriates these Anaxagorean tenets characterizing the overarching Mind, transferring the activity of global "domination" to the particular sphere of cognition (which surely does exhibit a transcendence of environmental limitations, insofar as knowledge entails the acquisition of form removed from confining material conditions) ${ }^{5}$ Furthermore, taken in its totality, the Aristotelian corpus converges to an endorsement of Anaxagoras's basic perspective, since Aristotle extends Mind's inherent freedom from matter to all intellectual substances in general (not only, as in De Anima III, to human beings qua rational). ${ }^{6}$

At any rate, Aristotle's philosophical procedure in the passage cited above seems prima facie legitimate (or at least plausible), presupposing Anaxagoras's doctrine necessitating the "unmixed" nature of an ordering Mind. Nevertheless, some obscurity arises from Aristotle's compressed expression of thought, thereby mandating the excavation of hidden premises or the insertion of whatever premises are required to make his enthymemic argument valid. With this background in view, I will address Aquinas's elucidation of Aristotle's condensed argument in De Anima III.

3. De Anima Г, 4: 429a18-29, trans. Hippocrates G. Apostle, in Aristotle's On The Soul (Grinnell, IA: The Peripatetic Press, 1981), pp. 49-50.

4. See Phaedo: 97c-98c, although Socrates (and, by probable inference, Plato himself) expresses disillusionment with Anaxagoras' failure to execute his metaphysical program beyond an incipient stage.

5. See De Anima II, 5: 418a3-6 and II, 12: 424a16-424b4, regarding sensation, but especially De Anima III, 8: 431b24-432a5, regarding intellection.

6. Cf. On Generation and Corruption II, 10: 336b30-35; Metaphysics XII, 7-9; Nicomachean Ethics X, 7: 1177b25-1178a8 and X, 8: 1178b8-32, 1179a20-30. 
First, in one question of his Quaestiones de Anima, Thomas succinctly explains:

$[\mathrm{S}]$ ince a human being is sometimes understanding in act and is sometimes only in potency to understand, we must admit that there is in a human being an intellective principle which is in potency to intelligible things. And this principle the Philosopher, in Book III of the De Anima, calls the possible intellect. The possible intellect must therefore be in potency to and able to receive all those things which are intelligible to a human being, and must therefore be devoid of all of them. This follows from the principle that whatever is capable of receiving things and is in potency to them is of itself without any of them, just as the pupil of the eye, which is capable of receiving all colors, has itself no color. Now a human being is naturally capable of understanding the forms of all sensible things. Consequently, the possible intellect must in itself be devoid of all sensible forms and natures, and as a result it is necessary that it have no bodily organ. For if it possessed a bodily organ, the possible intellect would be determined to a particular sensible nature; just as the power of sight is restricted to the nature of the eye. ${ }^{7}$

With minor rewording, he reiterates this argument for the spirituality of the human potential intellect in a later question of the same work:

Now it is clear that the principle by which a human being understands is a form that possesses existence and is not merely that by which something exists. For to understand, as the Philosopher proves in Book III of the De Anima, is not an act that is completed through a bodily organ. For it is impossible that there should be found a bodily organ which is capable of receiving all sensible natures, especially because a recipient must be free of the nature received, just as the pupil of the eye lacks color. Now every bodily organ has a sensible nature. On the other hand, the intellect by which we understand is capable of knowing all sensible natures. Hence it is impossible that the intellect's operation, which is to understand, be carried out through anything that is corporeal. Hence it is clear that the intellect has an essential operation in which its body does not share. ${ }^{8}$

Next, in the Summa Theologiae, Aquinas repeats virtually the identical formulation of the argument seen in the two foregoing paragraphs, but with additional illustrations:

It must necessarily be allowed that the principle of intellectual operation which we call the soul, is a principle both incorporeal and subsistent. For it is clear that by means of the intellect man can have knowledge

7. Questions on the Soul, q. 2, resp., trans. James H. Robb (Milwaukee, WI: Marquette University Press, 1984), p. 57.

8. Questions on the Soul, q. 14, resp., p. 177. 
of all corporeal things. Now whatever knows certain things cannot have any of them in its own nature; because that which is in it naturally would impede the knowledge of anything else. Thus we observe that a sick man's tongue being vitiated by a feverish and bitter humor, is insensible to anything sweet, and everything seems bitter to it. Therefore, if the intellectual principle contained the nature of a body it would be unable to know all bodies. Now every body has its own determinate nature. Therefore it is impossible for the intellectual principle to be a body. It is likewise impossible for it to understand by means of a bodily organ; since the determinate nature of that organ would impede knowledge of all bodies; as when a certain determinate color is not only in the pupil of the eye, but also in a glass vase, the liquid in the vase seems to be of that same color. Therefore, the intellectual principle which we call the mind or the intellect has an operation per se apart from the body. ${ }^{9}$

Lastly, in his Commentary on Aristotle's De Anima, Aquinas undertakes (as should be expected in a line-by-line commentary) a much more meticulous exegesis of the Greek philosopher's spirituality argument. Thomas begins by noting the correspondence between Anaxagoras's Mind (which must, according to Anaxagoras, be "unmixed" because it commands and moves all physical things) and the human mind treated by Aristotle (which must, according to Aristotle, be immaterial because of its potentially universal knowledge of material things). ${ }^{10}$ He then explicates the argument itself:

Anything that is in potency with respect to an object, and able to receive it into itself, is, as such, without that object; thus the pupil of the eye, being potential to colors and able to receive them, is itself colorless. But our intellect is so related to the objects it understands that it is in potency with respect to them, and capable of being affected by them (as sense is related to sensible objects). Therefore it must itself lack all those things which of its nature it understands. Since then it naturally understands all sensible and bodily things, it must be lacking in every bodily nature; just as the sense of sight, being able to know color, lacks all color. If sight itself had any particular color, this color would prevent it from seeing other colors, just as the tongue of a feverish man, being coated with a bitter moisture, cannot taste anything sweet. In the same way then, if the intellect were restricted to any particular nature, this connatural restriction would prevent it from knowing other natures. ${ }^{11}$

Next there occurs the concise formulation of what we shall henceforth call the "Impediment Principle": namely, "Intus apparens prohibet

9. Summa Theologiae I, q. 75, a. 2, c, trans. Fathers of the English Dominican Province, vol. II (1948; Westminster, MD: Christian Classics, 1981), 1:364.

10. In De Anima III, lect. 7, n. 679. Cf. Aristotle's De Anima in the Version of William of Moerbeke and the Commentary of St. Thomas Aquinas, trans. Kenelm Foster and Sylvester Humphries (London: Rutledge Keegan \& Paul, 1951), p. 404.

11. In De Anima III, lect. 7, n. 680, p. 405. 
extraneum."12 I translate this thesis as: "What appears within prevents what is outside (from coming in)." Interpreting Aristotle, Aquinas therapeutically analyzes this terminology: "He [Aristotle] calls 'the inwardly appearing' whatever may be supposed to be intrinsic and co-natural to the intellect and which, so long as it 'appeared' therein, would necessarily prevent the understanding of anything else." 13

The conclusion to be drawn is that, because the nature of the human mind is simply a power open to knowing the natures of all sensible things, it itself must be completely unencumbered by any sensible nature of its own. ${ }^{14}$ Not only is the human potential intellect uncomposed of matter in itself, but it cannot even operate directly through a corporeal organ:

In the same way sight would be impeded if it were the visual potency, not the pupil of the eye, that was colored. So he says that it comes to the same [thing] to maintain that intellect has no bodily organ and that it has no particular bodily nature; and concludes that the intellectual part of the soul, unlike the sensitive, has no bodily organ. ${ }^{15}$

Going beyond the literal surface of Aristotle's text in these excerpts, Aquinas supplies the same cluster of examples on the sensory level to illustrate the Impediment Principle. Evidently, he wants to emphasize that no human cognitive power, whether sensory or intellective, actually contains (or is innately endowed with) any of the proper objects of its knowledge. ${ }^{16}$ Otherwise, the definitive presence of such an object within it would thwart its reception of all the other objects belonging to that specific class to which it is in proximate potency. In consequence, the power, already actually determined in one particular way, would perceive all the different objects of the

12. In De Anima III, lect. 7, n. 680. (An alternative rendition of the Latin is "Intus apparens exterius prohibet.") When we revise the Impediment Argument later, however, we will refine and embellish the above English formulation of the Impediment Principle.

13. In De Anima III, lect. 7, n. 680, p. 405. J. A. Smith translates the Impediment Principle in the key text from Aristotle's De Anima as: "the co-presence of what is alien to its [the mind's] nature is a hindrance and a block" (see n. 2 above), whereas H. G. Apostle renders it as: "if it [the intellect] appears along [with some other thing], the [latter will] prevent or obstruct [the knowledge of] another kind [of thing]" (see n. 3 above). Smith's translation flows more smoothly and sounds more elegant than Apostle's, probably because Apostle is striving for greater literalness.

14. In De Anima III, lect. 7, n. 681, p. 405.

15. In De Anima III, lect. 7, n. 685, p. 406.

16. That is, those specifying qualities in the real world to which a power is essentially and primarily directed-determining forms to which no other power is radically oriented, and thus unique to the given power. The proper sensible objects will be enumerated with accompanying details later. Cf. De Anima II, 6, esp. 418a7-17, and Summa Theologiae I, q. 78, a. 3, ad 2. 
pertinent class in the same fixed manner-effectively nullifying the meaning of cognitive power as openness to various alternative instantiations of the class denoting its proper object.

Before embarking on a minute examination of Aquinas's version of Aristotle's Impediment Argument for the spirituality of the human potential intellect, I will review some pertinent theses from the metaphysics of knowledge that Thomas inherited from Aristotle (together with his own elaborations).

First, I shall stipulate (based on intuitive empirical observations) that not all beings can know: evidently, neither minerals nor plants. Knowledge enriches a living subject, opening it up to the attainment of the "forms" of other things without loss of its own proper forms and without concomitant acquisition of the "matter" of those objects (except possibly per accidens). Minerals do not actively take in forms at all; rather, they undergo passive reception of new forms while essentially enduring the departure (or "corruption") of their previous forms. Although plants (qua living beings) do exhibit a certain immanent teleology, engaging in goal-directed self-perfective activity, they can assimilate the forms of things (environmental nutrients) only along with the matter of those objects, as Aristotle peremptorily asserts. ${ }^{17}$ The objects of external vegetative activities thereby suffer destruction via incorporation. For both minerals and plants, forms can be acquired only subjectively: there is never any objective entertainment of the forms of other things as other.

Second, Aquinas incisively locates the fundamental reason for cognitive capacity in immateriality. Now, unlike the univocal notion of spirituality (which simply denotes intrinsic independence from matter), immateriality admits of gradations along a spectrum. Only prime matter, the ontological principle of pure potentiality underlying substantial change, is utterly "material" (so to speak). Every actual substance has some degree of form; otherwise, it could not exist as an entity in its own right. Some forms, however, are more circumscribed, in the being and activity that they confer, than others; they are more immersed within restrictive confinements that (for them) will never be transcended at higher levels of actuality. (We can therefore conceptualize matter in its state of unfulfilled potency as merely an intrinsic limitation of form, radically negating many possible perfections within the plenitude of existence. ${ }^{18}$ ) It is precisely their deeper submergence in materiality that makes minerals and even plants incapable of knowledge. By contrast, those beings more removed from the constrictions of materiality, such as brute animals and human persons, can escape their own subjective boundaries by reaching out to grasp the forms of other things. In short, immateriality is the very root of knowledge, since cognitive

17. De Anima II, 12: 424a33-424b3.

18. William Carlo, The Ultimate Reducibility of Essence to Existence in Existential Metaphysics (The Hague: Martinus Nijhoff, 1966), pp. 116-36, esp. p. 125. 
apprehension demands that the subject dematerialize (at least to some extent) the object. ${ }^{19}$

Thus, when Thomas declares (based on the principle "operatio sequitur esse") that a being can know only to the extent that it itself $i$ immaterial, he is not begging the question regarding the spirituality of the human mind. The two distinct concepts of "immateriality" and "spirituality" must not be confused. Aquinas's elucidation of the Aristotelian metaphysics of knowledge renders his use of the term 'immaterial' innocuous. Indeed, for Thomas (as well as Aristotle), the more actual or 'real' a substantial entity is, the greater is its 'immateriality.' But then, of course, the more profound issue of the spirituality-ontological independence from matter-of the human soul still remains as a looming question.

Hence, I will grant that, for a living being, knowledge consists in a teleologically perfective union (or identification) of subject with object as other, through the subject's immaterial possession of the object's form while retaining all its own natural form(s). The cognitive subject is able to disengage (assimilating without any destruction whatsoever) the object's form from the object's matter (its proper physical being in itself), whether this detachment of form from matter be partial (as in sensation) or total (as in intellection). ${ }^{20}$ I emphasize that this description of the perfection bestowed by knowledge applies only to a living being. I say this because someone might raise the fairly standard objection that reflecting surfaces (such as mirrors or the tops of clear aqueous bodies) also display the ability to receive the visible forms of things "immaterially" or objectively (without subjective loss of form in either the surface or the reflected thing), yet they are obviously noncognitive. However, this phenomenon characterizing the interplay between light waves and special surfaces does not satisfy the above descriptive definition of knowledge, because no holistically goal-directed enrichment accrues for the non-vital surface as a reaction to the sheerly passive apparition of images in it.

Moreover, I will concede that cognitive powers just are inherent psychic properties, that is, predicamental accidents necessarily flowing from the essence of the soul, whether brute animal or human. Such powers, considered in themselves, are purely potential with respect to the reception of other forms, although (unlike a reflecting surface) the living being actively exercises these powers for its own perfection and may subsequently enjoy the fruits of their contact with the real outside world. ${ }^{21}$

In the sequel, I will continually use the contrasting terms "natural" and "intentional" when distinguishing two types of presence of an accidental form within a cognitive power. By intentional presence, I mean the inner

19. Summa Theologiae I, q. 14, a. 1, c.

20. Summa Theologiae I, q. 14, a. 1, c; q. 78, a. 3, c; q. 84, a. 2, c, ad 2.

21. De Spiritualibus Creaturis, a. 11; Quaestiones de Anima, q. 12; Summa Theologiae I, q. 75, a. 1, ad 2; q. 77, a. 1, c; q. 79, a. 1, c, ad 1, 4. 
existence of a form that specifies or determines an act of knowledge as such. From our previous discussion of cognitional metaphysics, such a form is present 'immaterially' (in an analogical sense) within the knowing subject. On the other hand, by natural presence, I mean the internal existence of a form that enters into the ontic fabric of the very power itself. Such a form would therefore be present 'physically.' This definition of natural formal presence rules out another possible signification of natural : namely, a form endowed innately ("by nature") according to the mode of an infused idea, ever-present in a habitual manner (in "first act"), yet nevertheless superadded to the power.

The crucial issue, then, for Aquinas's rendition of the Impediment Argument revolves around whether cognitional hindrance would arise (a) from the natural (entitatively constitutive) presence or merely (b) from the intentional (cognitively specifying) presence of an actually informing proper object within the knowing power.

To clarify what is meant in (a), the power per se cannot, of course, be inherently qualified by a natural form, since it is simply a psychic potency and not an actual physical substance. However, per accidens, it can have a natural form if it operates intrinsically through a physical organ. In that case, the natural form of the organ might conceivably overwhelm the receptive capacity of the organ-power composite. This possible causal factor in frustrating knowledge of certain outward proper objects is the question (a) would address.

Dealing with (b) seems straightforward. If, for example, the imagination were continuously filled with pictures of circular shapes, triangular figures would always be excluded. Again, if someone's visual field were suffused with a definite design of tints and hues, this saturation would (in the measure of its duration) block out all other patterns of color. It is patently true that, in order to be open to the intentional reception of all members of the specific class comprising its proper object, a cognitive power must be $a$ priori devoid of their intentional presence. Otherwise, the abiding fulfillment of a cognitive potency under a definite formality would constantly determine it so completely as to close it off from other specific forms within that genus. This captivity of the knowing power by a mutinous insubordination rising from the ranks of its sovereign domain would seal its fate: it would be enthralled in the epistemic prison of a single dictating formality, unable (like a bound hostage) to accept communications from other forms within its proper dominion. Thus, cognitional hindrance would indeed occur, if there existed the intentional presence of an actually informing proper object within the knowing power. Lest the freedom guaranteed by knowledge be enervated or precluded, we infer that the intentional interference envisioned in (b) does not in fact obtain. ${ }^{22}$

22. The contents of this paragraph should not be misconstrued. For instance, it does not follow that the mind cannot apprehend a plurality of natures 
Yet, even though (b) has been settled, it does not automatically follow that the status of (a) is resolved. Aquinas's argument seems to entail the stronger tenet that (b) is not the sole way through which knowledge may be prevented, but that (a) is also a possibility to be faced. On the other hand, someone who disagrees may protest that the natural presence of an actually informing particular proper object is irrelevant to the successful intentional reception of all the proper objects within the purview of a given cognitive power. In other words, there is at least the theoretical possibility that the physical presence of a determinate proper object does not erect an insurmountable barrier thwarting the intentional entrance of all appropriate forms. The critical protestor might insist that the coincidence of both situations need not interfere with the activity of knowledge, because the two conditions are satisfied on diverse levels of being and hence not irreconcilably opposed. The critic might further claim to adduce concrete counterexamples to (a). For instance, he will admit that the gustatory power, functioning under normal circumstances, can intentionally receive all flavors. Yet if, say, a lamb's tongue (more exactly, its taste-bud regions) were excised and eaten, the consumer would detect a naturally present flavor, since the flesh is composed of tissues capable of definite chemical interactions with the consumer's tasting faculty. Similarly, the interior lining of the nostrils, with its scent-receptors open to accepting all aromas, would have its own peculiar odor. Thus, in neither case does the natural formal presence of a sensory power's proper object necessarily obstruct the intentional reception of all other members of the germane class of formal objects (whatever might be true for vision or even hearing). ${ }^{23}$

On the other hand, someone else might reply that the natural and intentional arenas, though assuredly distinguishable, are inextricably intertwined. In fact, as a sensory power operates directly through a bodily apparatus, it can be considered intentionally unreceptive to the extent that its organ is physically determined. For example, the auditory power cannot attain other sounds when structures in the inner ear are vibrating abnormally or are otherwise sealed off by a persistently obtrusive noise (as in the affliction of severe tinnitus). Hence, there is at least a practical approximation to an equivalence between intentional receptivity of a cognitive

simultaneously. In Summa Theologiae I, q. 85, a.4, Aquinas draws a distinction on this point. He concludes that, although the mind can be informed by only one intelligible species at a time, many things can be simultaneously understood provided they are subsumed under a single formality expressed by such a general idea.

23. I am indebted to Jeremy J. Lancey for bringing this problem to my attention and for some lively telephone conversations about it. At the time this article was written, he was a philosophy student at UCLA, where he had previously been exposed to the critical objection by Dr. Sean Kelsey, a professor in the UCLA Philosophy Department. The objection is also raised by Henry J. Koren, An Introduction to the Philosophy of Animate Nature (St. Louis: B. Herder Book Co., 1955), p. 166. 
power and freedom from natural determination. With regard to the above critic's counterexample concerning eating a lamb's tongue and perceiving the flavor of its taste-buds, the defender would be compelled to deny its refutational force. Based on the illustrations Aquinas evinces (highlighting sight and taste), these rejoinders undoubtedly reflect (for the most part) his own position. Yet a vexing ambiguity (as far as the critic is concerned) beclouds his discussion.

This whole question about the distinct kinds of formal presence (natural versus intentional) and their role in knowledge may not be momentous for the ontology of sensation, which, after all, is intrinsically psychosomatic. However, the issue is not so lightly dismissed in the realm of intellection: on the contrary, it is utterly crucial for the Impediment Argument, which purports to demonstrate the spirituality of the human potential intellect by using this sort of methodological tool. For, if the intentional reception of proper objects by cognitive powers can take place despite the natural presence of a physical form (which by hypothesis threatens no obstacle to knowledge), then the argument collapses and the mind's spirituality cannot be deduced through this reasoning process. In other words, when the distinction is explicitly drawn between intentional and natural presence of form, the cautious reader observes that the Impediment Argument as it stands seems to conflate the two kinds of presence in one blurred notion. The equivocation on the term "presence" thereby renders the desired inference invalid, begging the question with regard to the intellect's essential immateriality. The mind could conceivably function intrinsically through a physical organ (viz., the brain), if the natural presence of a material substantial form does not really prevent openness to intentional reception of the substantial forms of all material things.

One route out of this impasse would be to invoke the datum that the intellect, unlike the senses, can acquire universal (or absolute) formsa state of affairs that would not hold if the mind were physical (or an epiphenomenon of the brain), because matter constricts form, limiting it to the concrete singular (like a sensory percept or image). This approach, however, relies on the chief premise in a different demonstration: the proof from universal concepts. ${ }^{24}$ Thus, to take this avenue is tantamount to an admission of the probative inadequacy of the Impediment Argument.

Instead of confessing the irreparable unsoundness of the Impediment Argument (and thereby abandoning it), or else resorting to the expedient of importing an alien external premise (which amounts to abandoning it for lack of self-sufficiency), I will try to shore up the argument using an enhanced reconstruction. To this end, consider the following version of the 79.

24. Summa Theologiae I, q. 75, a. 5, c, ad 1; Summa contra Gentiles II, cc. 49, 50, 
Impediment Argument, whose steps (premises and intermediate conclusions, labeled "I" below) will be explained and defended subsequently.

I1. If a knowing power in essential potency to its proper object were by nature (that is, by virtue of the inner structure of its operation) to contain any particular item from this proper class, that actual presence would prevent the intentional reception of all other members of the class. (We will call this somewhat revised formulation the "Impediment Principle," designated IP.)

I2. The human intellect is a knowing power in essential potency to its proper object.

I3. The proper object of the human intellect is the essences of all material things.

I4. Suppose that the human intellect had a material nature (that is, one whose constitutive operation is intrinsically dependent upon matter).

I5. The human intellect is marked by the natural presence of one of its proper objects.

I6. The actual presence of this material nature prevents the intentional reception of all other material essences; equivalently, the human intellect is hindered in principle from understanding the natures of all material things.

I7. The essences of all material things are not the proper object of the human intellect.

I8. Hence, the human intellect does not have a material nature (that is, it is intrinsically independent of matter, which by definition means it is spiritual).

I contend that I1 (IP) is the only controversial statement in this recasting of the Impediment Argument, and so I will devote a protracted treatment to it after disposing of the rest of the steps.

First, the phrase "in essential potency," which occurs in the first two premises, is intended to contrast human with angelic intellection, in order to dismiss the latter from consideration here (assuming that such finite pure spirits exist at all). I therefore (while beseeching the reader's indulgent patience) take a detour into some speculative angelology.

According to Aquinas, since any mind can know only through a form somehow present in it, an angel's intellect in particular must be informed by distinct 'intelligible species' for precisely discerning those beings other than the angel itself. (It directly, intuitively, and transparently understands itself through its own essence.) These ideas are noetically determining media, innately bestowed on it from the first instant of its existence, because they are 
a connatural aspect of its perfection as an entity already fully realized. They adequately encompass the complete scope of an angel's natural cognitive capacity (although they do not constitute the 'nature' of the angelic mind itself, which is considered an accident of the angelic substance). Thus, an angel's strict immateriality liberates it from the need to gather its array of natural knowledge from finite external sources; it depends only on God's original infusion of ideas into its mind, and it knows by an introspective glance at them. In particular, since each angel's mind already contains an exemplary map of exact conformity with the cosmos, it certainly is not in a radical state of intentionally receptive potency to objects inhabiting the physical universe. ${ }^{25}$

Now, although the mental structure of each angel inherently includes all the intelligible likenesses pertaining to the entire gamut of its natural knowledge, it does not make use of all these imprinted species at the same moment in its actual understanding. With respect to its natural cognition, an angel can apprehend simultaneously only the plurality of those things subsumable under a single intentional form-not those contained under distinct intelligible similitudes. In other words, it cannot contemplate the whole spectrum of its native knowledge all at once. Hence, because it is not always exhaustively considering everything that it knows, the angelic mind undergoes an accidental transition from relative potency to exercised act when it decides to advert to and reflect on some continuously possessed epistemic datum. Despite the successiveness exhibited by angelic thought, it is a kind of sequentiality in which act follows act, rather than a mental movement (or discursion) from radical potency to act. Unlike the angelic mind, though, the human intellect labors under a condition of absolute or essential passive potentiality, acquiring new knowledge gradually from a privative state of primitive ignorance. Its mental operations are therefore (at the very least) extrinsically dependent on matter: namely, the raw materials provided by sensation and processed by the brain. As the angelic intellect is an engraved tablet, so the human potential intellect is initially a blank slate. ${ }^{26}$ Premise I2 should now appear manifestly true.

Next, one ought to grant premise I3 for the sake of justifying scientific endeavor and its roots in human curiosity or wonder, lest mankind's drive to explore the whole physical universe be relegated in principle to the otiose ${ }^{27}$

25. Summa Theologiae I, q. 55, a. 1, c, ad 3; q. 55, a. 2, c, ad 1; q. 56, a. 1, c, ad 2; q. 56, a. 2, c, ad 3; q. 57, a. 1, c, ad 1, 3; Summa contra Gentiles II, cc. 96, 98. We prescind here from Aquinas' pseudo-Dionysian theory of subordinated angelic illumination, propounded in Summa Theologiae I, q. 106, a. 1.

26. Summa Theologiae I, q. 58, a. 1, c, ad 3; q. 58, a. 2, c; q. 79, a. 2, c; Summa Theologiae I-II, q. 50, a. 6, c; Summa contra Gentiles II, cc. 98, 101.

27. For classical texts on wonder, incessant questioning, and humanity's natural unrestricted desire to know the causes of things, cf. Plato's Theaetetus: 155d; Aristotle's Metaphysics I,1 and I, 2; Bernard J. F. Lonergan, Insight (San Francisco: Harper \& Row, 1978), pp. 4, 9, 74, 221, 348-50, 380-81, 636, 701. 
The supposition in I4 commences a proof by contradiction. Then, taking I 4 as a hypothesis, I5 follows from I3 and I4. Since I2 and I5 together comprise the antecedent clause of I1 (IP), I6 (the consequent clause of IP) follows by modus ponens from I1 along with a substitution using I3. Because I7 (which follows from I6 by definition of the proper object of a power) contradicts I3, the supposition in I 4 must be false. Thus, we must affirm I8, and the desired result is established.

It remains to defend IP. IP can be supported either (A) on general metaphysical grounds or else (B) by a proof utilizing induction and analogy. Each argument for IP will be outlined with no concomitant remarks, but then a justification for the reasoning involved will immediately ensue. (The steps in the first argument will be labeled by alpha-numeric couplets starting with "A," whereas those in the second argument will start with "B.")

\section{Argument A}

A1. Assume the existence of a knowing power $\mathrm{P}$, in essential potency to its proper object, that possesses by its very nature (that is, by dint of its internal constitution and intrinsic operation) the actual presence of a particular member $\mathrm{M}$ of the class comprising its proper object.

A2. The natural presence of a form in a cognitive power is a first determinant of that power's operation. ${ }^{28}$

A3. A first natural determinant of a cognitive power's operation remains as a filter through which all other members of its proper object class must pass.

A4. $\mathrm{M}$ is a first natural determinant of $\mathrm{P}$.

A5. All other members of P's proper object class must pass through $\mathrm{M}$ as a filter.

A6. Whatever is filtered cannot, as such, be received objectively (as it is in itself).

A7. All members of P's class of proper object (other than M) are in principle hindered from objective cognitive reception by $\mathrm{P}$.

A8. IP obtains.

At this point we comment on the steps of Argument A. A1 is the antecedent clause of IP (which was expressed as a conditional statement). This hypothesis, of course, gets the argument moving.

Among all the steps in this argument, A2 is probably the one most vulnerable to dispute. In its favor, we first remind ourselves that a power in

28. This is a generalization of a proposition enunciated by Koren, Philosophy of Animate Nature, p. 166. 
itself, by definition, is a sheer potentiality ordered to activity; thus, a psychic power is a capacity for vital functioning and a cognitive power is a pure ability to know (whether perceptually or conceptually). Hence, a naturally present form in a cognitive power would serve as a more immediate source of knowledge than the power itself, since such a form would be an ever-present actualization of a less proximate potency. The power would therefore not be activated except through this constantly intervening formal principle. Consequently, it would be an initial determinant of all subsequent cognitive activity emanating from that power, which is what A2 declares. Moreover, since knowledge entails the immaterial reception of form, no further form could be intentionally acquired except through this prior determining formality. In other words, no other aspects of the power's proper object class could escape the influence of this pervasive form: they would all inexorably be filtered through it, which is precisely the assertion of A3.

Now A1 and A2 together obviously imply A4, while A3 and A4 together imply A5. As for A6 (also a debatable proposition not immune to attack), a given cognitive power could not claim direct access to any form that must first pass through another naturally present form. Because the latter form would be a prior actualization of the power, the power's status as a raw receiver would thereby be compromised. The filtering form would create an inevitable distortion of any other entering form, in principle frustrating its objective reception by the power. Knowledge would not, then, provide a reliable channel to its supposed object. (A realist epistemology is, of course, assumed here.)

Now A7, which is the consequent clause of IP, follows from the conjunction of A5 and A6. Since the hypothesis A1 implies the conclusion A7, by the Deduction Rule the conditional statement expressed by IP holds. This ends the proof of IP via Argument A, and we pass to the second argument for IP.

\section{Argument B}

B1. IP is satisfied for each of the five external sensory powers and their correlative proper objects.

B2. IP is a hierarchical precept that applies analogically throughout the domain of cognitive powers in essential potency to their proper objects.

B3. The human potential intellect is a cognitive power in essential potency to its proper object (the natures of all material things).

B4. IP holds most perfectly for the human potential intellect.

I will verify the first premise above by a complete enumeration. I grant as experiential facts that the proper object of sight is color; of hearing is 
sound; of smelling is odor; of tasting is flavor; and of touch is temperature and pressure differentials. ${ }^{29}$ Next, please permit me the following somewhat naïve pronouncements, which will require subsequent qualification. The pupils of the eyes are black, lacking a natural color; otherwise, the constant actual presence of some color would cause them to see everything in light of that definite hue (as if covered by tinted glasses), preventing the vision of all other colors. The ears lack a natural sound of their own, or else they would be hindered from hearing all other sounds. An inherent aroma is absent from the nose; otherwise, it would be inhibited from smelling other fragrances. The tongue is not normally burdened with an actual flavor of its own, or else it would taste everything in that way. The tactile receptors in the skin are indeed impeded from intentionally receiving all temperatures and pressures due to the natural presence of temperature and pressure: they can detect only temperatures and pressures that deviate from those naturally present. Nevertheless, there is no natural temperature or pressure differential besetting the sense of touch; otherwise, the perpetual presence of a fixed differentiating determination would block the discrimination of other ranges of tactile difference.

So all five external senses seem to obey IP. But here is where some nuanced sophistication is needed. For the sake of advancing a general metaphysical principle (viz., IP), Aquinas evidently deemed it obligatory (or at least advantageous) to flesh out Aristotle's sketchy text. As they stand, however, his bald extra-Aristotelian illustrations perhaps somewhat overstate the case for IP. After all, to say (for example) that the pupil of the eye is colorless idealizes the empirical facts. No part of any vital organ (or of any body, even a transparent substance like unadulterated water) is literally bereft of all pigmentation; otherwise, it would be utterly invisible. Even light frequencies not discernible by unaided human sight (infrared or ultraviolet) in some sense share the attribute of color. ${ }^{30}$ In fact, they may be perceptible to some animals with a more acute ocular system than ours; however, such "colors" (in the broad sense) do not truly fall under the proper object of human vision and thus can be considered incidental to sight. Just as there can be relatively thin surfaces approaching planar flatness and relative states of vacuum approaching a total void, neither one of which really exists in our tridimensional plenum, so also the absence of natural form in a sensory power is only approximate. Every sense power, being psychosomatic, seems naturally informed to some degree (varying among animal species), but those

29. Aristotle expends much effort on an in-depth study of the five external senses and their proper objects. See, for example, De Anima II, 6-11. For a more modern treatment with physiological details, see Michael Maher, Psychology (1918; Albany: Magi Books, 1982), pp. 63-88.

30. With regard to the notion of "visibility", see Aristotle's De Anima II, 7: 418a29418b4, esp. (according to the J. A. Smith translation in the McKeon ed.): "Whatever is visible is colour." (p. 567) and "Light is as it were the proper colour of what is transparent." (p. 568). 
determinations lying outside a certain perceptual boundary have a per accidens relation to the sense as such (qua cognitive potency). Since they do not orbit within the sphere per se of a sense power's proper object, the amount of obstruction they pose for sensory knowledge is assuredly minimal.

To rebut the critic's counterexample described earlier, the tissues in which the taste-buds of a lamb's tongue are embedded could indeed have a flavor to an exterior percipient. Yet, according to the inner experience of the lamb itself, these neural complexes as such are perceptually subliminal quasi-objects: for all practical purposes, they are tasteless and hence capable of perceiving virtually all flavors. ${ }^{31}$ Likewise for the taste-buds of the one eating the lamb's tongue! On the other hand, if the taste-bud regions were coated by an infecting substance that temporarily acted after the manner of a natural form, the tale would be different. The invasion by an extraneous form of flavored material-a proper object in the true sense-would intentionally determine their potency, inhibiting them (for the duration) from perceiving other flavors.

In sum, on account of the existence of threshold values or tenuous pseudo-objects (which, nevertheless, do not essentially intrude into the proper ambit of sensation), the natural deprivation of sensible forms as a standard for intentional reception of proper objects is not absolute, but holds only to a certain (albeit high) degree of approximation. To the extent that the organ of a sense power were naturally informed by a specific instance of its proper object class, though, that sense power could not intentionally receive all aspects of its proper object class: some would elude capture. ${ }^{32}$ Hence, interpreted in a subtle way, IP does prevail for the five senses. Therefore, B1 is established.

An aside concerning the consistency of Argument B with Argument A. The genuine objectivity of sensation urged in the defense of A6 does not conflict with the acknowledgment of some natural formal determination admitted in the discussion of B1. Because such formalization is beyond the pale (so to speak), Argument B merely recognizes the circumscribed dominion of sensory activity without impeaching its integrity, its competence to disclose things as they really are.

Aquinas expounds in some detail how the five external senses are hierarchically ordered according to their degree of immateriality. Among these senses, sight reigns at the apex of immateriality, because it involves no physical change on the part of either object or subject. (With respect to the subject, Aquinas seems to be taking a macroscopic viewpoint, because some microscopic chemical reactions occur inside the eye from the action of

31. Of course, no sensory power can perceive its own activity, because such selfreflection is beyond any material power. But this fact is part of another argument also favored by Aquinas. See n. 37 below.

32. George P. Klubertanz, The Philosophy of Human Nature (New York: AppletonCentury-Crofts, Inc., 1953), p. 163. 
lightwaves.) Hearing comes in second place, because it requires atmospheric vibration induced by locomotion on the part of the object. (Again, structures inside the subject's ears are at least incidentally affected by soundwaves.) Smelling occupies the third rung of the ladder, because the object must undergo chemical alterations in order to emit vapors, while the subject's nasal passages inhale fumes. The least removed from matter are taste and touch, because these two senses demand direct physical contact between subject and object, with both entities experiencing natural change (albeit more so for the organ of touch than taste).$^{33}$

Due to this hierarchical arrangement, IP does not apply in an univocal way to each of the five senses. Rather, IP fits proportionately to the degree that a sensory function surpasses matter with regard to knowing subject and/or known object. In other words, IP holds analogically within the arena of external sensation. By the way, this explains why the critic's objection to IP focuses more on difficulties for taste and touch than for hearing and sight: it is easier to accept IP on the higher sensory levels than on the lower ones.

At any rate, if there were a cognitive power whose activity (or correlative proper object) transcended even the noblest sense faculty, then it is reasonable to extrapolate that IP would continue to obtain in an analogous fashion for such a power. It seems inconceivable that IP, which expresses a noetic-ontic condition (or even perfection, at least for knowing beings who are hylomorphic substances and not pure spirits), would suddenly fail at a superior level of reality. Thus, for any cognitive power (in essential potency to its proper object), we ought to grant that IP is analogically true to a degree based on the power's standing in the hierarchy of knowledge. This much is what B2 maintains.

Now, according to historical experience, the human mind suffers (in principle) no hindrance to its potential knowledge of the general natures of all material things; otherwise, open-ended scientific investigation would be excluded as a theoretical impossibility. ${ }^{34}$ Hence, since its proper object exceeds in dignity the proper objects of sensation, from B2 and B3 the human potential intellect also obeys IP. Indeed, on account of the mind's consummate (virtually infinite) excellence compared with the senses, the analogous character of IP implies that the human potential intellect satisfies IP most perfectly, as B4 declares. Consequently, whatever perplexities may attend IP in the sensory sphere, derogating from its exact truth there, no residue of doubt should plague IP in the intellectual realm. Herein, the inferior approximations to IP vanish (as happens in a calculus limiting process), and IP emerges as completely true for the human potential intellect. It must, therefore, subjectively lack any material nature whatsoever.

Fortunately, even if my attempt to fully vindicate the Impediment Argument falls short of its goal due to lingering suspicions about its soundness

33. Summa Theologiae I, q. 78, a. 3, c, ad 3, 4; Quaestiones de Anima, q. 13, resp.

34. Revert to n. 27 above. 
(whether the truth of its premises or the validity of its logic), there are other (perhaps more convincing) demonstrations for the spirituality of the human potential intellect: for example, Aristotle's Excessive Intensity Argument, ${ }^{35}$ the Universal Concepts Argument,${ }^{36}$ and Aquinas's Reflexive Self-Consciousness Argument. ${ }^{37}$ Nonetheless, despite the existence of other proofs, it would be gratifying to succeed at salvaging the Impediment Argument from the criticism of its detractors. For, as one author has proclaimed: "[I] ts profound metaphysical implications make it extremely difficult.... Yet it is his [Aquinas's] most powerful argument ... best calculated to refute the errors of the materialists." 38 Aquinas indubitably thought it cogent; else, he would not have showcased it without reservation on several occasions. We can question the assessment of its persuasive force and complain that the argument's metaphysical puzzles (or troublesome features) might actually be incompatible with its practical value. On the other hand, it does confront anyone (whether inclined to materialism or not) engaged in the philosophical enterprise with a fascinating challenge for intellectual penetration.

35. De Anima III, 4: 429a29-429b4.

36. Revert to n. 24 above.

37. Summa contra Gentiles II, c. 49. This argument occurs in seminal form in De Anima III, 4: 429b9 (J. A. Smith in the McKeon ed., p. 590): “[T] he mind ... is ... able to think itself."

38. Henri Renard, The Philosophy of Man (Milwaukee, WI: The Bruce Publishing Company, 1948), p. 30. 